\title{
NuMA in rat testis-Evidence for roles in proliferative activity and meiotic cell division
}

\author{
Pekka Taimen, ${ }^{\mathrm{a}, \mathrm{b}, *}$ Martti Parvinen, ${ }^{\mathrm{c}}$ Mary Osborn, ${ }^{\mathrm{d}}$ and Markku Kallajoki ${ }^{\mathrm{a}}$ \\ ${ }^{a}$ Department of Pathology, University of Turku, FIN-20520 Turku, Finland \\ ${ }^{\mathrm{b}}$ Turku Graduate School of Biomedical Sciences, Turku, Finland \\ ${ }^{\mathrm{c}}$ Department of Anatomy, University of Turku, FIN-20520 Turku, Finland \\ ${ }^{\mathrm{d}}$ Department of Biochemistry, Max Planck Institute for Biophysical Chemistry, 37077 Göttingen, Germany
}

Received 13 April 2004, revised version received 13 April 2004

Available online 15 June 2004

\begin{abstract}
NuMA is a well-characterized organizer of the mitotic spindle, which is believed to play a structural role in interphase nucleus. We studied the expression of NuMA in rat seminiferous epithelium in detail. Different stages of the cycle of the seminiferous epithelium were identified using transillumination. Corresponding areas were microdissected and analysed using immunofluorescence, immunohistochemistry, or immunoblotting. NuMA was expressed in Sertoli cells, proliferating type A and B spermatogonia, and early spermatids but it was absent in late spermatids and mature spermatozoa. Interestingly, NuMA-positive primary spermatocytes lost their nuclear NuMA at the beginning of long-lasting prophase of the first meiotic division. A strong expression was again observed at the end of the prophase and finally, a redistribution of NuMA into pole regions of the meiotic spindle was observed in first and second meiotic divisions. In immunoblotting, a single $250-\mathrm{kDa}$ protein present in all stages of the rat seminiferous epithelial cycle was detected. Our results show that NuMA is not essential for the organization of nuclear structure in all cell types and suggest that its presence is more likely connected to the proliferation phase of the cells. They also suggest that NuMA may play an important role in meiotic cell division.
\end{abstract}

(C) 2004 Elsevier Inc. All rights reserved.

Keywords: NuMA; Nuclear matrix; Testis; Spermatogenesis; Differentiation; Interphase nucleus; Meiosis

\section{Introduction}

NuMA (Nuclear-Mitotic Apparatus) is a large nuclear protein that accumulates to the spindle poles in mitosis [1]. Studies using microinjection [2-5] and immunodepletion [5-7] and expression studies with truncated forms of NuMA [8] have shown that NuMA is required for normal mitotic spindle assembly. NuMA is phosphorylated in the $\mathrm{G}_{2} / \mathrm{M}$ transition, presumably by cdc2/cyclin $\mathrm{B}[5,9-11]$. NuMA then forms a complex with the motor protein dynein and dynactin resulting in a minus-end directed transport of NuMA along microtubules to the spindle pole regions [7]. The association of NuMA with the mitotic spindle is thought to be regulated by the nuclear import receptor importin $\beta$ and a small GTPase Ran $[12,13]$. According to this model,

* Corresponding author. Department of Pathology, University of Turku, MediCity Research Laboratory, Tykistökatu 6A, 4th Floor, FIN-20520, Turku, Finland. Fax: +358-2-333-7000.

E-mail address: pekka.taimen@utu.fi (P. Taimen). importin $\beta$ binds and inhibits NuMA but during mitosis Ran-GTP blocks importin $\beta$ to release NuMA for spindle assembly. Other data has shown that NuMA directly interacts with microtubules (MTs) with its C-terminal tail $[14,15]$. This association is inhibited by another component of the mitotic spindle, LGN, which also binds to the Cterminus of NuMA [16,17]. The MT and LGN binding domains of NuMA have an overlap of 10 amino acids so LGN might block the majority of endogenous NuMA during mitosis so as to ensure normal bipolar spindle assembly. Thus far, only two studies have studied NuMA during meiotic cell division. In pig and mouse oocytes, NuMA appeared to localize to spindle poles of the meiotic cells and treatment with nocodazole disrupted the localization of NuMA [18]. In maturating Xenopus oocytes, the microinjection of NuMA antibodies perturbed the organization of the transient MT array and the meiotic spindle [19]. Both studies suggest a role for NuMA in oocyte meiosis. The function of NuMA in spermatogenic meiotic cell division, however, is still unknown. 
Due to an essential role in mitosis, less attention has been paid to the function of NuMA during interphase. The primary structure of NuMA, composed of globular aminoand carboxy-terminal domains and a long $\alpha$-helical rod domain [20,21], resembles that of the intermediate filament proteins, perhaps supporting the idea that NuMA might have a structural role in the interphase nucleus. Indeed, NuMA is a highly insoluble component of the nuclear matrix and in overexpression experiments regular three-dimensional lattice-like NuMA structures have been described [22,23]. Like lamins, the nuclear intermediate filament proteins, NuMA appears to bind directly to chromatin [24]. Thus, NuMA might organize the chromatin structure in the interphase nucleus. These hypotheses have been supported by several studies in which NuMA has been shown to be cleaved during apoptosis [25,26] and necrosis [27] as well as during virus-induced cell death [28]. They provide further support for the idea that the cleavage of NuMA may be a critical step in the degradation of the nuclear structure.

On the other hand, other data suggests that NuMA is not expressed in all cell types. Merdes and Cleveland [29] observed the absence of NuMA in several mouse cell types, including spermatozoa, granulocytes, and some differentiated smooth and skeletal muscle cells. They also showed that NuMA is not essential in nuclear assembly: The addition of human sperm DNA to frog egg extract immunodepleted of NuMA resulted in nuclei with a normal appearance [29]. We have previously shown that some highly differentiated (e.g., spermatozoa and some neurons) and nonproliferating human cell types (e.g., syncytiotrophoblasts and the superficial keratinocytes) lack NuMA [30]. Disappearance of NuMA has also been described in vitro in differentiating C2F3 mouse myoblasts [29], in MCF-7 human breast cancer cells [30], and in ROS 17/2.8 rat osteosarcoma cells [31] during extended culture. All these studies suggest a nonessential role for NuMA in the interphase nucleus.

In the present study, we further studied the role and expression of NuMA in differentiating cells in the seminiferous epithelium of testis, which shows a well-characterized differentiation process from a stem cell to a terminally differentiated haploid spermatozoon. In addition, this gave us the possibility of studying the role of NuMA in spermatogenic meiotic cell division. The cycle of the rat seminiferous epithelium can be divided into 14 stages [32]. First, spermatogonial stem cells ( $\mathrm{A}_{\mathrm{s}}$ spermatogonia) either renew themselves or differentiate by dividing into $A_{p r}$ (paired) spermatogonia that remain connected by an intercellular bridge. $A_{\text {pr }}$ spermatogonia divide further to form chains of 4,8 , or $16 \mathrm{~A}_{\mathrm{al}}$ (aligned) spermatogonia, which then go through six mitotic divisions to produce $A_{1}, A_{2}, A_{3}$, $\mathrm{A}_{4}$, intermediate, and finally type $\mathrm{B}$ spermatogonia [33]. Type B spermatogonia give rise to primary spermatocytes, which after meiotic prophase go through meiotic cell divisions to form secondary spermatocytes and further spermatids. Spermatids finally differentiate and elongate into mature spermatozoa. The cells of the spermatogenic series are supported and nurtured by Sertoli cells $\left(S_{t}\right)$, whereas the tubular wall is composed of basal membrane and myoid cells.

Our results show that although NuMA is expressed in the majority of spermatogenic cell types, it is absent in leptotene, zygotene, and early pachytene primary spermatocytes, late spermatids, and mature spermatozoa. Moreover, NuMA seems to be a prominent component of the meiotic spindle. This data strongly suggests that NuMA is only expressed in the nuclei of proliferatively active cells and during certain phases of the first meiotic prophase and spermiogenesis.

\section{Materials and methods}

\section{Animals and tissue preparation}

Adult Sprague-Dawley rats obtained from the Central Animal Laboratory, University of Turku, were killed by $\mathrm{CO}_{2}$ asphyxiation. The testes were removed, decapsulated, and the seminiferous tubules were dissected in a Petri dish containing $24^{\circ} \mathrm{C}$ PBS $\left(145 \mathrm{mM} \mathrm{NaCl}, 7.5 \mathrm{mM} \mathrm{Na}_{2} \mathrm{HPO}_{4}\right.$, $2.8 \mathrm{mM} \mathrm{NaH}_{2} \mathrm{PO}_{4}$ ) under a transilluminating stereomicroscope. Different stages of rat seminiferous epithelium were identified using the transillumination technique as previously described [34]. For squash preparations, 0.5-1.0-mm segments from seminiferous tubule were cut and transferred with a pipettor on a microscope glass in $15 \mu \mathrm{l}$ of PBS. The sample was carefully covered with an $18 \times 18 \mathrm{~mm}$ cover glass and the excess fluid was removed by blotting. The exact stage of the cycle was determined under phase-contrast microscope using the morphological criteria of Leblond and Clermont [32]. The samples were further snap frozen in liquid nitrogen, the cover slips were removed, and the samples were fixed in acetone for 5-10 min. After fixation, the microscope slides were air-dried for 5-10 min or stored in PBS at $+4{ }^{\circ} \mathrm{C}$ for a maximum time of $48 \mathrm{~h}$ before processing for immunofluorescence. When tubulin staining was done, segments from seminiferous tubule were transferred on a microscope glass in 15-30 $\mu$ l of microtubule stabilizing buffer (MTSB: $4 \mathrm{M}$ glycerol, $0.1 \mathrm{M}$ PIPES, $\mathrm{pH}$ 6.8, $1 \mathrm{mM}$ EGTA, 5mM $\mathrm{MgCl}_{2}$; [35]) and covered with a cover glass for $10 \mathrm{~min}$ before the liquid nitrogen step.

\section{Antibodies and reagents}

The SPN-7 mouse monoclonal NuMA antibody detecting an epitope in the N-terminal part of human, rat, and mouse NuMA was used as undiluted culture supernatant in immunofluorescence and at a 1:20 dilution in immunoblotting $[2,36]$. In immunohistochemistry, SPN-7 ascites fluid was used as a 1:1000 dilution. The SPN-3 mouse monoclonal NuMA antibody detecting an epitope in the N-terminal region of human NuMA (AA 255-267) was used as undiluted culture supernatant in immunofluorescence 
$[2,3,36]$. Affinity-purified rabbit polyclonal tubulin antibody [37] was used at a 1:5 dilution. FITC-conjugated goat anti-mouse IgG was purchased from Cappel Laboratories (Cochranville, PA), biotinylated horse anti-mouse IgG and biotinylated goat anti-rabbit IgG from Vector Laboratories (Burlingame, CA) and streptavidin labeled Texas red from Sigma. Peroxidase-labeled secondary antibody was sheep anti-mouse IgG (Amersham, Buckinghamshire, UK).

\section{Immunohistochemistry}

Fresh capsulated testis was snap frozen in liquid nitrogen for a few seconds. Frozen sections of $6 \mu \mathrm{m}$ were cut, placed on a microscope slide, fixed in $-20^{\circ} \mathrm{C}$ acetone for $10 \mathrm{~min}$, and stored at $-20^{\circ} \mathrm{C}$. Tissues were reacted with primary antibody (SPN-7) or for controls with 1\% BSA in PBS. The primary immunoreaction was localized using a Vectastain avidin-biotin complex peroxidase (ABC) kit (Vector) according to the manufacturer's instructions. The sections were counterstained with hematoxylin. All samples were analyzed using an Olympus BX 50 light/fluorescence mi- croscope (Olympus Optical Co. LTD, Tokyo, Japan) and AnalySIS software (Soft Imaging Systems).

\section{Immunofluorescence microscopy}

Squash preparations and frozen sections from whole testis were pretreated with 5\% normal goat serum (Vector) in PBS for $30 \mathrm{~min}$, washed three times with PBS, and incubated with NuMA antibody (SPN-7 clone) or with NuMA and tubulin antibodies in a humid chamber for $2 \mathrm{~h}$ at room temperature. Slides were washed three times with PBS and then incubated with biotinylated horse anti-mouse antibody $(1: 100)$ or with biotinylated goat anti-rabbit (1:200) and FITC-conjugated goat-anti-mouse (1:50) secondary antibodies in 1\% BSA in PBS for $1 \mathrm{~h}$ at room temperature, washed again three times with PBS and then incubated with streptavidin-labeled Texas Red (1:50-100) in 1\% BSA in PBS for $1 \mathrm{~h}$. After washing three times with PBS, samples were stained for DNA with Hoechst $33258(1 \mu \mathrm{g} / \mathrm{ml}$ in $25 \%$ ethanol $/ 75 \%$ PBS $)$ for $5 \mathrm{~min}$ and embedded in Mowiol 4.88 (Hoechst AG, Frankfurt, Germany).
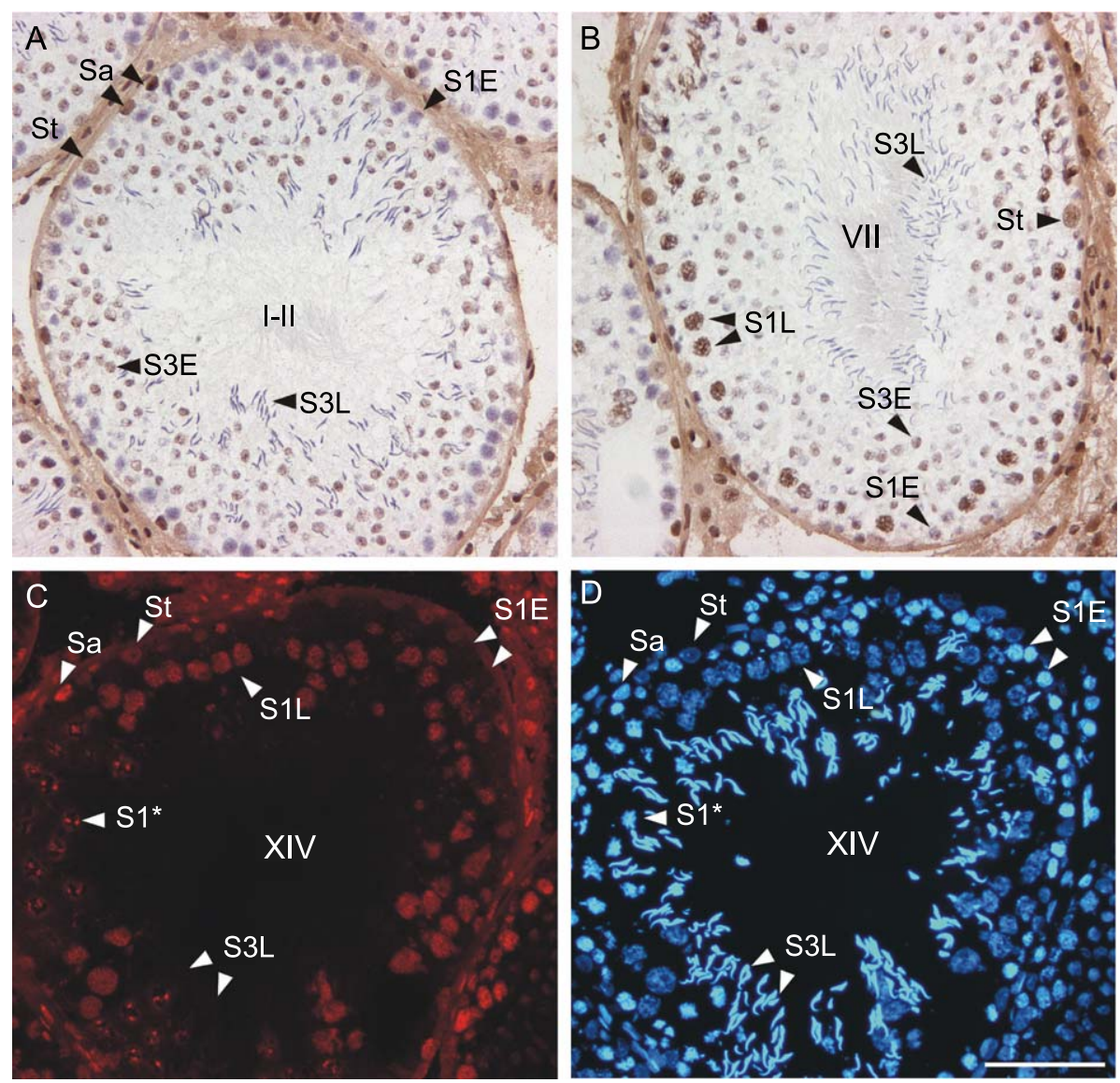

Fig. 1. The localization of NuMA in rat testis. Frozen sections of rat testis tissue were fixed in acetone and reacted with NuMA antibody (SPN-7). The primary immunoreaction was localized by using an avidin-biotin complex peroxidase kit (A, B) or with biotinylated horse-anti-mouse secondary antibody and streptavidin-labeled Texas red (C). Sections A and B were counterstained with hematoxylin. Section C was counterstained for DNA with Hoechst (shown in D). Basal differentiating type A spermatogonia (Sa) are strongly NuMA-positive. Early pachytene spermatocytes (S1E) are negative whereas late pachytene and diakinetic spermatocytes (S1L) are positive. NuMA is expressed in early spermatids (S3E) but it is absent in late spermatids (S3L). Sertoli cells (St) are weakly positive. In meiotic spermatocytes $\left(\mathrm{S} 1^{*}\right)$, NuMA is relocated to the spindle poles. Scale bar is $50 \mu \mathrm{m}$. 


\section{Electrophoresis and immunoblotting}

For immunoblotting six $0.5-\mathrm{cm}$ segments from seminiferous tubules, approximately 300,000 cells were prepared for each of following stage pools: II-VI, VII-VIII, IX-XII,
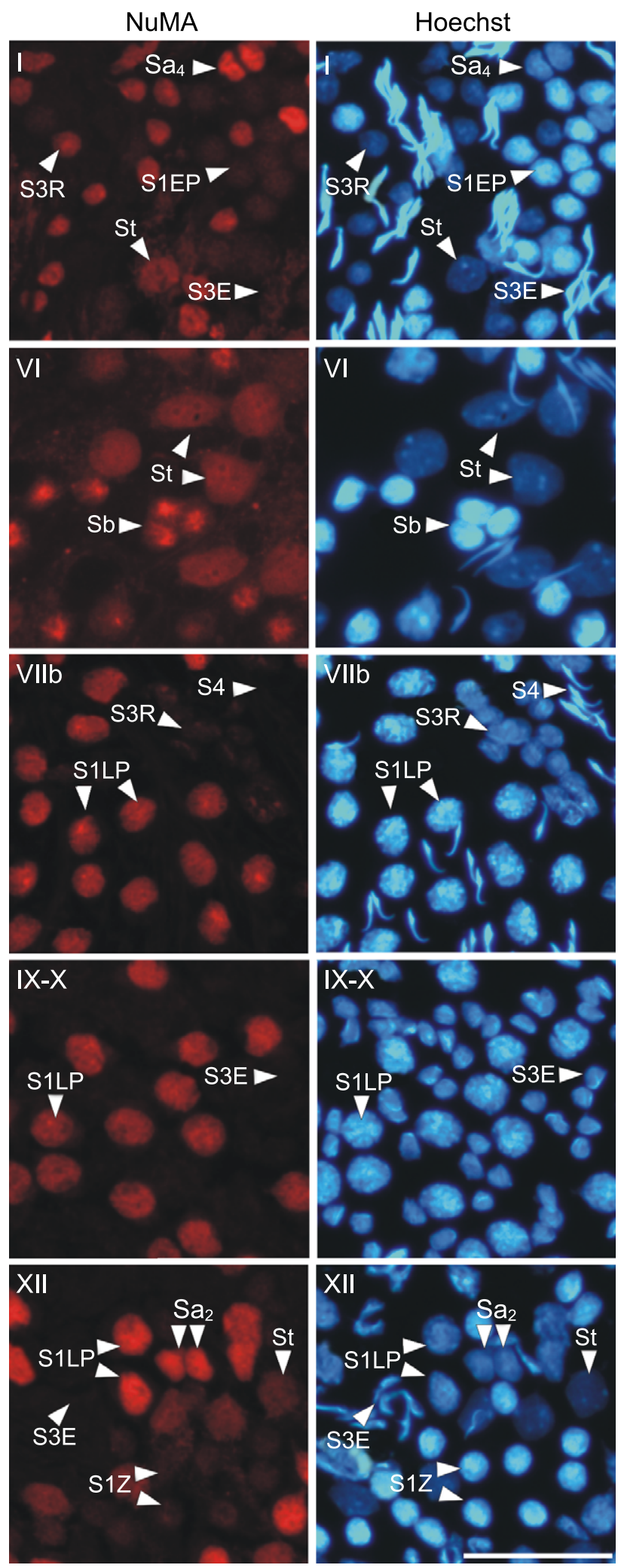

XIII-I. Cells were suspended directly into $50 \mu \mathrm{l}$ of hot SDS-PAGE electrophoresis sample buffer, sonicated for $5 \mathrm{~s}$, and used in SDS-PAGE. Proteins were separated electrophoretically in 5\% polyacrylamide gels. Two parallel gels were run: one for Coomassie brilliant blue staining to confirm equal loading and another for immunoblotting. Proteins were transferred electrophoretically to nitrocellulose (Schleicher \& Schuell, Dassel, Germany) in a buffer containing $25 \mathrm{mM}$ Tris, $192 \mathrm{mM}$ glycine, 0.05\% SDS, and $10 \%$ methanol at $300 \mathrm{~mA}$ constant current for $1.5 \mathrm{~h}$. The transfer was controlled by Ponceau red staining. The filters were preincubated in $4 \%$ bovine serum albumin (BSA) in $0.2 \%$ Tween 20 in TBS (Tris buffered saline: $20 \mathrm{mM}$ Tris$\mathrm{HCl}, \mathrm{pH} 7.4,0.15 \mathrm{mM} \mathrm{NaCl}$ ) for $1 \mathrm{~h}$, washed twice with $0.2 \%$ Tween 20 in TBS, and incubated with the primary antibody diluted in $1 \%$ BSA, $0.2 \%$ Tween 20 in TBS for $2-$ $3 \mathrm{~h}$ at room temperature, or for $16 \mathrm{~h}$ at $+4{ }^{\circ} \mathrm{C}$. The filters were then washed three times with $0.2 \%$ Tween 20 in TBS and incubated for $1 \mathrm{~h}$ at room temperature with peroxidaselabeled secondary antibody diluted $1: 3000$ in $1 \%$ BSA, $0.2 \%$ Tween 20 in TBS. After four washes with $0.2 \%$ Tween 20 in TBS, the immunoreactivity was detected by using enhanced chemiluminescence reaction (ECL Western blotting detection system, Amersham). When filters were to be reused, they were first washed with $0.2 \%$ Tween 20 in TBS, then incubated at $+50^{\circ} \mathrm{C}$ with stripping buffer $(2 \%$ SDS, $100 \mathrm{mM}$ ß-mercaptoethanol, $63 \mathrm{mM}$ Tris, $\mathrm{pH}$ 6.8) for $1 \mathrm{~h}$ and finally washed four times with $0.2 \%$ Tween 20 in TBS before preincubation in $4 \%$ BSA.

\section{Results}

NuMA is not present in all cell types of rat spermatogenic epithelium

Two mouse monoclonal NuMA antibodies, SPN-3 and SPN-7 [2], were tested in immunofluorescence with rat

Fig. 2. The expression of NuMA in different stages of rat spermatogenic cycle. Squash preparations from different stages of the spermatogenic cycle were isolated using transillumination-assisted microdissection. Samples were squashed, snap frozen in liquid nitrogen, and fixed in acetone. Samples were stained with NuMA primary antibody (SPN-7), biotinylated horse-anti-mouse secondary antibody, and streptavidin-labeled Texas red. Samples were counterstained for DNA with Hoechst. Stage I shows NuMApositive Sertoli cells (St), type $\mathrm{A}_{4}$ spermatogonia $\left(\mathrm{Sa}_{4}\right)$, and early round spermatids (S3R). Early pachytene spermatocytes (S1EP) and late elongated spermatids (S3E) are NuMA-negative. Stage VI shows several Sertoli cells (St) and mitotic type B spermatogonia ( $\mathrm{Sb}$ ). In stage VIIb, strongly positive primary spermatocytes in late pachytene can be seen (S1LP). Round spermatids (S3R) have lost their nuclear NuMA and mature spermatozoa (S4) are totally negative. In stages IX-X, late pachytene spermatocytes (S1LP) have grown in size and spermatids (S3E) have started to elongate. In stage XII, negative or only weakly positive zygotene spermatocytes (S1Z) and elongated spermatids (S3E) are shown. Sertoli cells (St), type $\mathrm{A}_{2}$ spermatogonia $\left(\mathrm{Sa}_{2}\right)$, and late pachytene spermatocytes (S1LP) are NuMA-positive. Scale bar is $50 \mu \mathrm{m}$. 
fibroblasts. Only the SPN-7 antibody reacted with rat NuMA showing a diffuse or slightly granular staining of the interphase nuclei excluding nucleoli and a bipolar staining of the mitotic spindles (not shown). In human cervix carcinoma cells (HeLa), both SPN-7 and SPN-3 antibodies gave identical staining patterns (not shown).

To document the distribution of NuMA in different cell types of rat seminiferous epithelium, sections from adult rat testis were stained with SPN-7 antibody using immunohistochemistry. Because the SPN-7 antibody did not react with paraffin-embedded tissue, frozen sections were used. Immunohistochemical staining showed that NuMA was present in the majority of cell types but also that some differentiated cell types such as late spermatids and mature spermatozoa lacked NuMA (Figs. 1A,B). In addition, some basal cell types were negative in certain stages of the cycle.

To better verify the NuMA-positive and -negative cell types, immunofluorescence was used. Primary antibody reaction was detected by the biotin-streptavidin method and the cells were counterstained for DNA. As shown in Figs. 1C,D, type A spermatogonia, late primary spermatocytes, early spermatids, and Sertoli cells were positive while early spermatocytes and all late spermatids and mature spermatozoa were negative for NuMA. Interestingly, several cells showed bipolar NuMA staining. These cells obviously represent a population of primary spermatocytes in meiotic cell division, which takes place in stage XIV of the cycle.
NuMA is present in proliferatively active phases of spermatogenesis

Fig. 2 shows squash preparations taken from defined stages of the cycle. In stage I, a few strongly positive oval or longitudinal nuclei were observed representing type $\mathrm{A}_{4}$ spermatogonia. The largest NuMA-positive cell population was formed by early spermatids, which had just passed the second meiotic division in stage XIV. Interestingly, early pachytene spermatocytes, which can be distinguished from haploid early spermatids using the DNA stain, were negative for NuMA. Late spermatids and spermatozoa were negative as expected from the immunohistochemical analysis. Sertoli cells were positive in stage I as well as in other stages of the cycle.

In stages II-V, no striking changes in the NuMA distribution were detected. There was increased NuMA staining in pachytene spermatocytes after stages III and IV, whereas staining of the early round spermatids became weaker. The maturation of type B spermatogonia into preleptotene spermatocytes is characterized by a mitotic peak in stage VI [38]. In dividing cells, NuMA relocated to the spindle poles in an aster-like shape (Fig. 2) and thereafter to the nuclei of the daughter cells. Stage VII, which lasts more than 2 days in rat, is typically divided into four subtypes (VIIa, b, c, and d). During substages VIIa-b, NuMA staining of the round spermatids markedly decreased and finally in stage VIIc they were negative (Fig.
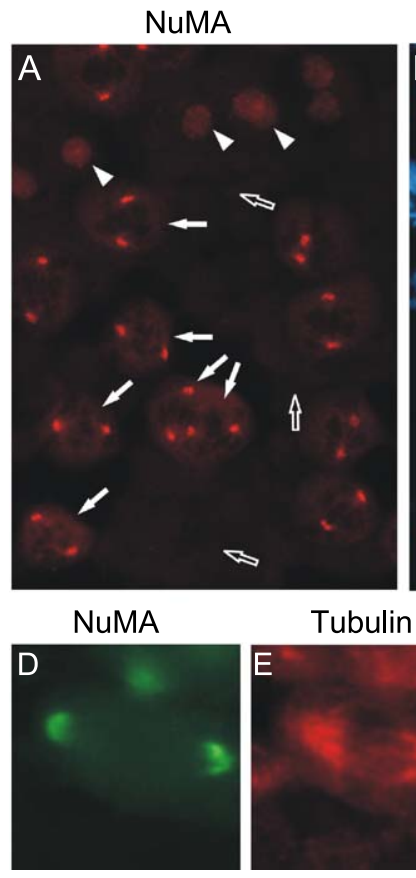
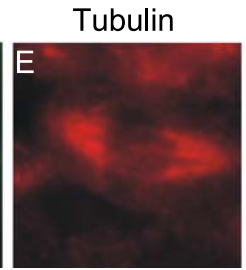

Hoechst
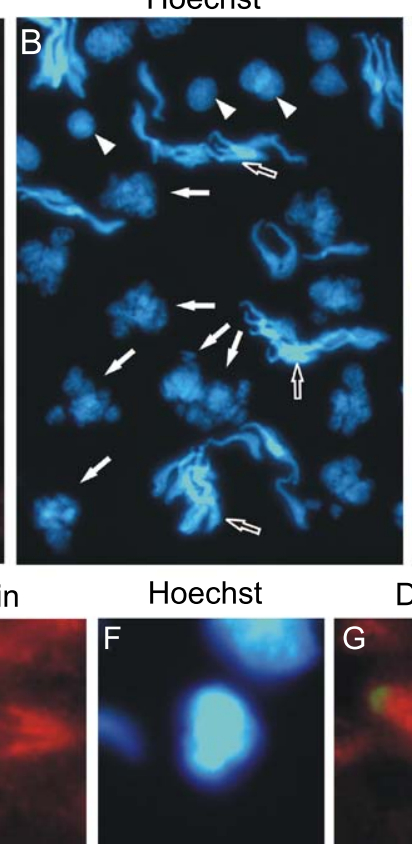

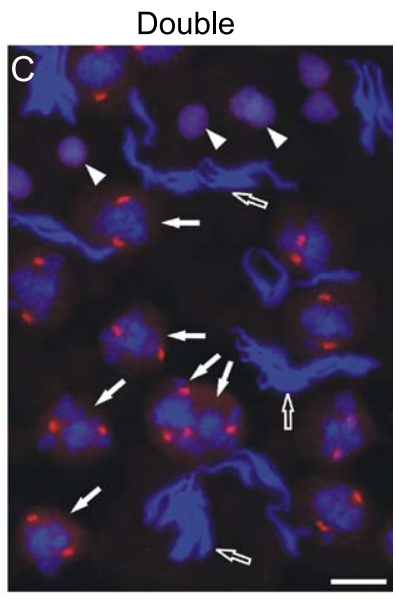

Double
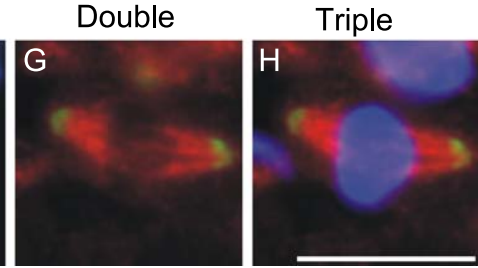

Fig. 3. NuMA is localized to the spindle pole in meiotic spermatocytes. Squashed segments of stage XIV of the cycle containing dividing primary and secondary spermatocytes were isolated using transillumination-assisted microdissection. Samples were stained with NuMA primary antibody (SPN-7; A), biotinylated horse-anti-mouse secondary antibody, and streptavidin-labeled Texas red or with NuMA (D) and tubulin (E) primary antibodies, FITC-conjugated goat-anti-mouse and biotinylated goat-anti-rabbit secondary antibodies and streptavidin-labeled Texas red. Samples were counterstained for DNA with Hoechst. In first $(\mathrm{A}-\mathrm{C})$ and second $(\mathrm{D}-\mathrm{H})$ meiotic division, NuMA is redistributed to the pole regions in meiotic spindle (arrows). Secondary spermatocytes (A-C, arrowheads) are NuMA-positive, whereas elongated spermatids (A-C, open arrows) are negative. Scale bar is $10 \mu \mathrm{m}$. 
2 and data not shown). The nuclei of primary spermatocytes in midpachytene grow rapidly in size in stage VII and the intensity of the nuclear NuMA stain also increased. In stage VIII, release of mature spermatozoa was observed. Because the majority of the cells were NuMA-negative round spermatids and mature spermatozoa, only a minor proportion of the cells, e.g., dividing type A spermatogonia, preleptotene spermatocytes, midpachytene spermatocytes, and Sertoli cells were NuMA positive at this stage. The stages IX-XI last only 1 day in the rat. At that time, spermatids elongated (Fig. 2) and already in stage XII they had the recognizably elongated long nuclei typical of this stage (Fig. 2). By then, leptotene and zygotene spermatocytes in early prophase had also almost totally lost NuMA as shown in Fig. 2.

The final phase of meiotic prophase, diplotene, in stage XIII is short and the primary spermatocytes then enter the first meiotic division. In stage XIV, a dramatic redistribution of NuMA to the pole regions of the meiotic spindle was observed (Fig. 3) with NuMA present in spindle poles in both first and second meiotic divisions. To ensure that these cells were meiotic, triple staining for NuMA, tubulin, and DNA was done. As shown in Figs. 3D-H, NuMA colocalized with MT minus ends in meiotic spindles. This suggests that NuMA organizes the tubulin attachment to the spindle poles in spermatogenic meiotic as well as in mitotic spindles.

\section{NuMA is equally expressed in all stages of rat seminiferous epithelial cycle}

The presence of NuMA in all stages of rat seminiferous epithelial cycle was confirmed by Western blotting. Fourteen stages were pooled into four groups and six $0.5-\mathrm{cm}$ segments from each group were isolated and prepared for SDS-PAGE. SPN-7 antibody detected one $>200-\mathrm{kDa}$ protein in all samples showing that NuMA is present in equal amounts in all the subgroups (Figs. 4 and 5). No testisspecific isoforms were observed. In a control sample from whole rat testis, an additional approximately $200-\mathrm{kDa}$ isoform was detected. This isoform was not detected in any of the subgroups, which suggests that it is probably present in surrounding interstitial tissue but not in spermatogenic epithelium. The comparison of rat and human NuMA revealed that rat NuMA has a higher apparent molecular weight than the $238 \mathrm{kDa}$ characteristic of human NuMA.

\section{Discussion}

According to the data shown here, NuMA seems to be a nonessential structural protein of the nucleus, which is preferentially expressed in proliferatively active cells. This is consistent with our earlier results [30] as well as with the results of Merdes and Cleveland [29]. In the latter study, the majority of NuMA negative cells had a nonspherical (e.g.,

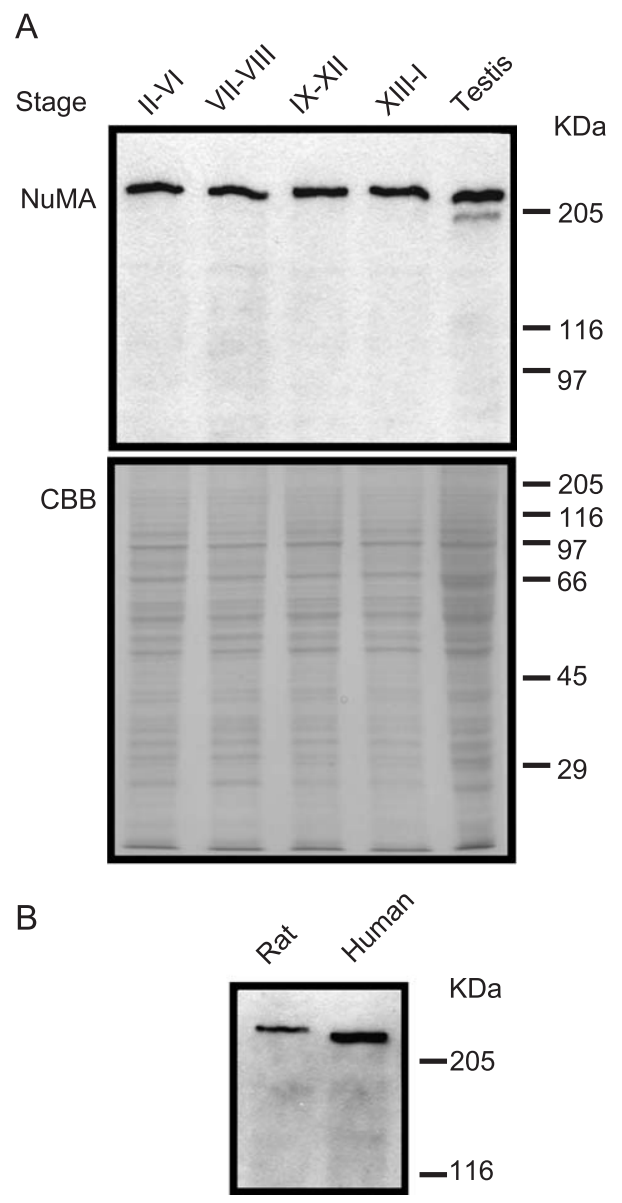

Fig. 4. Western blot analysis of rat NuMA. (A) Western blot analysis of different stages of rat seminiferous tubule. Six $0.5-\mathrm{cm}$ segments from seminiferous tubules were prepared for each of following pools: II-VI, VII-VIII, IX-XII, XIII-I, and samples were prepared for SDS-PAGE. Total extract from rat testis was used as a control. Two parallel gels were run: one for Coomassie brilliant blue staining (CBB) to confirm equal loading and another for immunoblotting with NuMA antibody (SPN-7). NuMA is present in all stages of rat spermatogenic cycle. In the whole testis, an additional approximately $200-\mathrm{kDa}$ protein is detected. (B) Comparison of molecular weight of rat and human NuMA. Cultured rat fibroblasts and human cervix carcinoma cells (HeLa) were prepared for SDS-PAGE and immunoblotted with NuMA antibody (SPN-7). Rat NuMA has higher apparent molecular weight (approximately $250 \mathrm{kDa}$ ) than human NuMA $(238 \mathrm{kDa})$

elongated or beaded) nuclear morphology and the authors speculated that the absence of NuMA could lead to a change in the nuclear structure. We later showed that some human cell types with spherical nuclei (keratinocytes, neurons, and spermatogenic cells) also lack NuMA. In the present study, the elongated spermatids were devoid of NuMA but the primary spermatocytes in the first meiotic prophase also lost NuMA without any significant changes in nuclear morphology. This suggests that the lack of NuMA does not necessarily result in nonspherical nuclear structure.

One aim of this study was to investigate whether NuMA has any testis-specific isoforms. NuMA binds to defined DNA sequences called matrix attachment regions (MARs), 


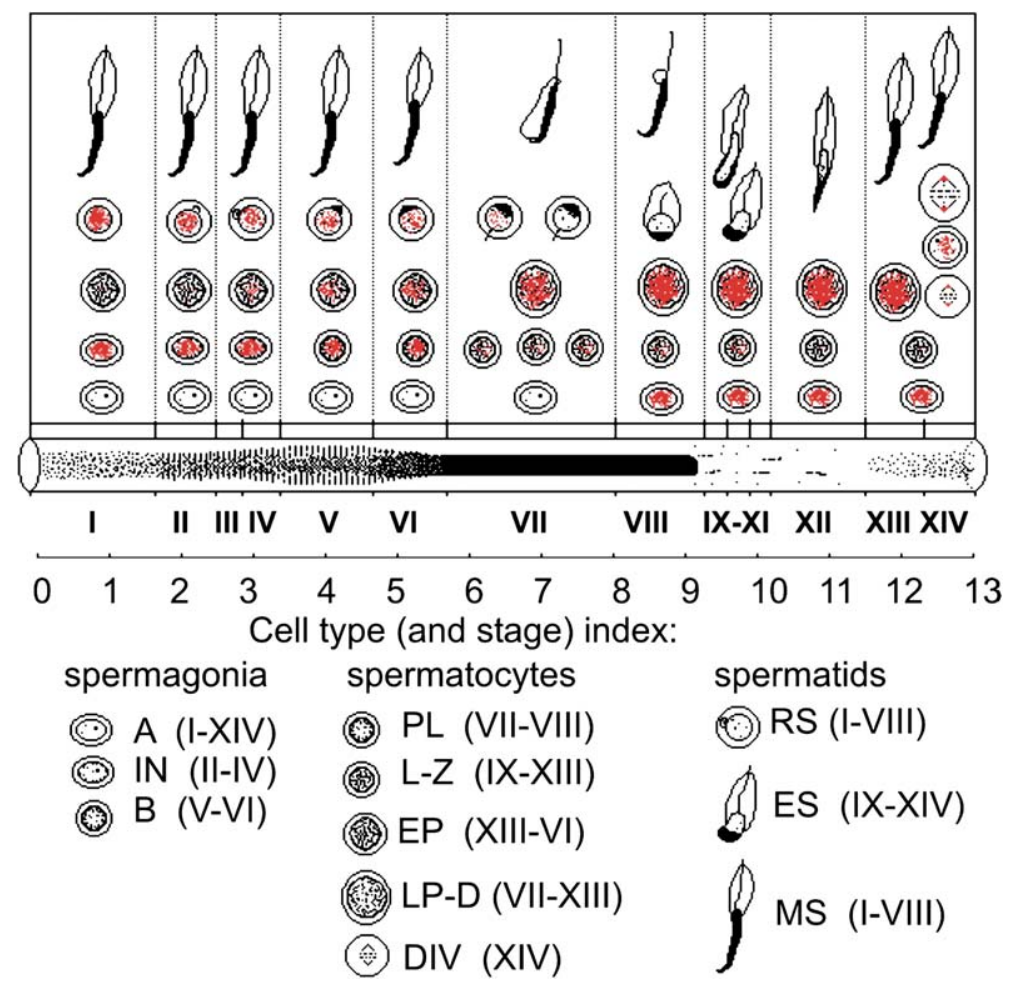

Fig. 5. The expression profile of NuMA in different stages of rat seminiferous epithelial cycle. The figure summarizes the data shown in Figs. $1-3$. The expression of NuMA is shown in red. Different stages of rat seminiferous epithelium are shown in Roman numbers and the corresponding transillumination pattern of the seminiferous tubule is shown above. The duration of the stages in days is shown in Arabic numbers and different cell types and the stages in which they are present are shown at the bottom. Abbreviations are as follows: A, type A; IN, intermediate; B, type B; PL, preleptotene; L, leptetene; Z, zygotene; EP, early pachytene; LP, late pachytene; D, diakinetic; DIV, division; RS, round spermatid; ES, elongated spermatid; MS, mature phase spermatid.

as do lamins [24]. Lamins, the intermediate filament proteins forming the nuclear lamina, have two isoforms (lamin B3 and C2), which are only expressed in spermatogenic cells $[39,40]$. Interestingly, the expression of lamin B3 in cultured somatic cells results in transformation of the nuclear morphology from spherical to hook-shaped nuclei suggesting that lamin B3 is involved in reorganization of the nuclear and chromatin structures during spermatogenesis [39]. Our immunoblotting data for NuMA show only one single protein band present in all stages of the seminiferous epithelial cycle. This was supported by RT-PCR experiments using combinations of six primer pairs specific for NuMA (data not shown). The lack of testis-specific NuMA isoforms is surprising, because smaller NuMA isoforms were detected in whole testis extract (Fig. 4) and in several other rat tissues (data not shown). Smaller isoforms, most likely generated by alternative mRNA splicing, have also been described in different human cell lines [41]. In summary, the existing data suggests that NuMA does not have testis-specific isoforms, which could play a role in the differentiation process during spermatogenesis.

During the first meiotic prophase, we noticed a decrease followed by a strong reexpression of NuMA in primary spermatocytes (Fig. 2). Moreover, there were significant differences between the amounts of nuclear NuMA in different cell types. This suggests that the expression and the amount of NuMA depend on the proliferation status of a cell. In other words, NuMA is highly expressed in type A and $\mathrm{B}$ spermatogonia and late pachytene and diakinetic primary spermatocytes, which later will undergo several cell divisions. During meiotic chromosome pairing in zygotene and during recombination in early pachytene, NuMA expression was minimal or absent. These cells, as well as elongating and maturating spermatids and mature spermatozoa, are not proliferating and do not express NuMA. This also gives a rough estimate of how quickly the cells may lose their nuclear NuMA: the prophase of the first meiotic cell division takes approximately 3 weeks in rat. During this period of time, leptotene, zygotene, and early pachytene spermatocytes are NuMA-negative for more than 1 week. This resembles the results of the in vitro experiments, in which the reduction of NuMA expression was detected after a few days culture [29-31]. The expression of NuMA in mid and late pachytene primary spermatocytes and in round spermatids, however, is not related to cell proliferation, because no DNA replication occurs in these cells. It may reflect a long half life of intranuclear NuMA. On the other hand, the expression pattern quite clearly follows the RNAsynthetic activity of these cells $[42,43]$. In haploid cells, NuMA disappears shortly before the cessation of RNA synthesis at stage VIII, and during the beginning of the storage period of several haploid-cell-specific genes [44]. 
These observations suggest that NuMA may have a role in chromatin remodeling and transcriptional activity during late meiosis and early spermiogenesis.

In meiotic primary and secondary spermatocytes, an accumulation of NuMA at the spindle poles was observed (Fig. 3). Thus, the involvement of NuMA in spermatogenic meiotic spindle assembly seems similar to that showed in mitosis. Previously, relocalization of NuMA to the spindle poles in pig and mouse as well as in Xenopus meiotic oocytes was observed [18,19]. Lee et al. [18] also showed that in the pig meiotic spindle NuMA unexpectedly relocalized to the spindle midzone during anaphase and telophase. They concluded that because mammalian oocytes, unlike spermatocytes, lack centrioles [45], the movement of the segregated chromosomes may pass the position occupied by spindle poles during mitosis and the polarity of meiotic spindle MTs may become inverted. In spermatogenic meiotic late anaphase and telophase, we detected a relocalization of NuMA to the reforming daughter nuclei similar to mitosis. Because mature spermatozoa lack NuMA, it is maternal NuMA that contributes to the organization of the mitotic spindle in the first cell division after fertilization.

Some questions remain. First, what is the role of NuMA in the interphase nucleus? It was reported earlier that overexpression of NuMA lacking the nuclear localization signal (NLS) results in lattice-like NuMA structures in the cytoplasm, suggesting that NuMA may have a structural function in the interphase nucleus $[22,46]$. However, recent reports have shown that exogenous NuMA in the cytoplasm directly binds to MTs $[15,17]$ and possibly these filamentous structures are, at least partially, composed of MTs. The nuclear localization may therefore be just a simple mechanism to store NuMA until the next cell division and to avoid NuMA-MT interaction during interphase. On the other hand, knockdown of NuMA expression using RNA interference (RNAi) results in apoptosis showing that NuMA is an essential gene at least in cultured HeLa cells [47]. There is no doubt that NuMA is essential in mitotic cells, but there is not enough data how silencing affects the nuclear structure of the interphase cells and it is thereby possible that the apoptosis was induced because the cells could not complete mitosis. Another important issue is the meaning of apoptotic cleavage of NuMA. Many of the caspase target proteins cleaved during apoptosis, e.g., lamins, fodrin and actin [48], are structural and it would be tempting to put NuMA into the same category. On the other hand, there are several other cellular proteins, the cleavage of which seems to play a homeostatic or no role at all. One possibility is that the cleavage of NuMA is a cellular mechanism to prevent mitotic activity. To finally solve this question, apoptosis experiments with cells expressing uncleavable NuMA mutants may be required.

NuMA was the first nuclear protein described that had a functional role in mitotic spindle assembly. Recently, sev- eral other nuclear proteins with similar cell-cycle-dependent localization have been found. These include TPX2 [49], Nup358 [50], and NuSAP [51], all of which have essential functions in the mitotic spindle. So far, no particular function has been found to these proteins in the interphase nucleus. Therefore, one possibility is that the localization of these proteins is a way developed during evolution to store critical mitotic proteins in the nucleus to prevent their contact with cytoplasmic mitotic proteins and thereby avoid possible harmful effects in interphase.

\section{Acknowledgments}

We would like to thank Yangyang Wang, Liisa Lempiäinen, Janne Suominen, and Jaakko Liippo for technical assistance. Jorma Toppari is acknowledged for his expertise and comments on the figures. This work was supported by grants from the Paulo Foundation, Emil Aaltonen Foundation, The Finnish Medical Foundation, Turku University Foundation, Medical Faculty of University of Turku, and the Cultural Foundation, the Regional Fund of Varsinais-Suomi. P.T. is a recipient of a studentship from Turku Graduate School of Biomedical Sciences (TuBS).

\section{References}

[1] B.K. Lyderson, D.E. Pettijohn, Human-specific nuclear protein that associates with the polar region of the mitotic apparatus: distribution in a human/hamster hybrid cell, Cell 22 (1980) 489-499.

[2] M. Kallajoki, K. Weber, M. Osborn, A $210 \mathrm{kDa}$ nuclear matrix protein is a functional part of the mitotic spindle; a microinjection study using SPN monoclonal antibodies, EMBO J. 10 (1991) $3351-3362$.

[3] M. Kallajoki, J. Harborth, K. Weber, M. Osborn, Microinjection of a monoclonal antibody against SPN antigen, now identified by peptide sequences as the NuMA protein, induces micronuclei in PtK2 cells, J. Cell Sci. 104 (1993) 139-150.

[4] C.H. Yang, M. Snyder, The nuclear-mitotic apparatus protein is important in the establishment and maintenance of the bipolar mitotic spindle apparatus, Mol. Biol. Cell 3 (1992) 1259-1267.

[5] T. Gaglio, A. Saredi, D.A. Compton, NuMA is required for the organization of microtubules into aster-like mitotic arrays, J. Cell Biol. 131 (1995) 693-708.

[6] T. Gaglio, A. Saredi, J.B. Bingham, M.J. Hasbani, S.R. Gill, T.A. Schroer, D.A. Compton, Opposing motor activities are required for the organization of the mammalian mitotic spindle pole, J. Cell Biol. 135 (1996) 399-414.

[7] A. Merdes, K. Ramyar, J.D. Vechio, D.W. Cleveland, A complex of NuMA and cytoplasmic dynein is essential for mitotic spindle assembly, Cell 87 (1996) 447-458.

[8] D.A. Compton, D.W. Cleveland, NuMA is required for the proper completion of mitosis, J. Cell. Biol. 120 (1993) 947-957.

[9] C.A. Sparks, E.G. Fey, C.A. Vidair, S.J. Doxsey, Phosphorylation of NUMA occurs during nuclear breakdown and not mitotic spindle assembly, J. Cell Sci. 108 (1995) 3389-3396.

[10] D.A. Compton, C. Luo, Mutation of the predicted p34cde2 phosphorylation sites in NuMA impair the assembly of the mitotic spindle and block mitosis, J. Cell Sci. 108 (1995) 621-633.

[11] K. Gehmlich, L. Haren, A. Merdes, Cyclin B degradation leads to 
NuMA release from dynein/dynactin and from spindle poles, EMBO Rep. 5 (2004) 97-103.

[12] M.V. Nachury, T.J. Maresca, W.C. Salmon, C.M. Waterman-Storer, R. Heald, K. Weis, Importin beta is a mitotic target of the small GTPase Ran in spindle assembly, Cell 104 (2001) 95-106.

[13] C. Wiese, A. Wilde, M.S. Moore, S.A. Adam, A. Merdes, Y. Zheng, Role of importin-beta in coupling Ran to downstream targets in microtubule assembly, Science 291 (2001) 653-656.

[14] M. Kallajoki, K. Weber, M. Osborn, Ability to organize microtubules in taxol-treated mitotic PtK2 cells goes with the SPN antigen and not with the centrosome, J. Cell Sci. 102 (1992) 91-102.

[15] L. Haren, A. Merdes, Direct binding of NuMA to tubulin is mediated by a novel sequence motif in the tail domain that bundles and stabilizes microtubules, J. Cell Sci. 115 (2002) 1815-1824.

[16] Q. Du, P.T. Stukenberg, I.G. Macara, A mammalian Partner of inscuteable binds NuMA and regulates mitotic spindle organization, Nat. Cell Biol. 3 (2001) 1069-1075.

[17] Q. Du, L. Taylor, D.A. Compton, I.G. Macara, LGN blocks the ability of NuMA to bind and stabilize microtubules. A mechanism for mitotic spindle assembly regulation, Curr. Biol. 12 (2002) 1928-1933.

[18] J. Lee, T. Miyano, R.M. Moor, Spindle formation and dynamics of gamma-tubulin and nuclear mitotic apparatus protein distribution during meiosis in pig and mouse oocytes, Biol. Reprod. 62 (2000) $1184-1192$.

[19] B.E. Becker, S.J. Romney, D.L. Gard, XMAP215, XKCM1, NuMA, and cytoplasmic dynein are required for the assembly and organization of the transient microtubule array during the maturation of Xenopus oocytes, Dev. Biol. 261 (2003) 488-505.

[20] D.A. Compton, I. Szilak, D.W. Cleveland, Primary structure of NuMA, an intranuclear protein that defines a novel pathway for segregation of proteins at mitosis, J. Cell Biol. 116 (1992) 1395-1408.

[21] C.H. Yang, E.J. Lambie, M. Snyder, NuMA: an unusually long coiled-coil related protein in the mammalian nucleus, J. Cell Biol. 116 (1992) $1303-1317$.

[22] C. Gueth-Hallonet, J. Wang, J. Harborth, K. Weber, M. Osborn, Induction of a regular nuclear lattice by overexpression of NuMA, Exp. Cell Res. 243 (1998) 434-452.

[23] J. Harborth, J. Wang, C. Gueth-Hallonet, K. Weber, M. Osborn, Self assembly of NuMA: multiarm oligomers as structural units of a nuclear lattice, EMBO J. 18 (1999) 1689-1700.

[24] M.E. Luderus, J.L. Den Blaauwen, O.J. De Smit, D.A. Compton, R. Van Driel, Binding of matrix attachment regions to lamin polymers involves single-stranded regions and the minor groove, Mol. Cell. Biol. 14 (1994) 6297-6305.

[25] C. Gueth-Hallonet, K. Weber, M. Osborn, Cleavage of the nuclear matrix protein NuMA during apoptosis, Exp. Cell Res. 233 (1997) 21-24.

[26] P. Taimen, M. Kallajoki, NuMA and nuclear lamins behave differently in Fas-mediated apoptosis, J. Cell Sci. 116 (2003) 571-583.

[27] R. Bortul, M. Zweyer, A.M. Billi, G. Tabellini, R.L. Ochs, R. Bareggi, L. Cocco, A.M. Martelli, Nuclear changes in necrotic HL-60 cells, J. Cell. Biochem. Suppl., (2001) 19-31.

[28] P. Taimen, H. Berghäll, R. Vainionpää, M. Kallajoki, NuMA and nuclear lamins are cleaved during viral infection-Inhibition of caspase activity prevents cleavage and rescues HeLa cells from measles virus- but not from rhinovirus 1B-induced cell death, Virology 320 (2004) 85-98.

[29] A. Merdes, D.W. Cleveland, The role of NuMA in the interphase nucleus, J. Cell Sci. 111 (1998) 71-79.

[30] P. Taimen, M. Viljamaa, M. Kallajoki, Preferential expression of NuMA in the nuclei of proliferating cells, Exp. Cell Res. 256 (2000) $140-149$.

[31] K. Torrungruang, H. Feister, D. Swartz, E.B. Hancock, J. Hock, J.P. Bidwell, Parathyroid hormone regulates the expression of the nuclear mitotic apparatus protein in the osteoblast-like cells, ROS 17/2.8, Bone 22 (1998) 317-324.

[32] C.P. Leblond, Y. Clermont, Definition of the stages of the cycle of the seminiferous epithelium in the rat, Ann. N. Y. Acad. Sci. 55 (1952) $548-573$.

[33] D.G. De Rooij, Proliferation and differentiation of spermatogonial stem cells, Reproduction 121 (2001) 347-354.

[34] M. Parvinen, T. Vanha-Perttula, Identification and enzyme quantitation of the stages of the seminiferous epithelial wave in the rat, Anat. Rec. 174 (1972) 435-449.

[35] M.B. Gordon, L. Howard, D.A. Compton, Chromosome movement in mitosis requires microtubule anchorage at spindle poles, J. Cell Biol. 152 (2001) 425-434.

[36] J. Harborth, K. Weber, M. Osborn, Epitope mapping and direct visualization of the parallel, in-register arrangement of the doublestranded coiled-coil in the NuMA protein, EMBO J. 14 (1995) $2447-2460$.

[37] M. Osborn, R.E. Webster, K. Weber, Individual microtubules viewed by immunofluorescence and electron microscopy in the same PtK2 cell, J. Cell Biol. 77 (1978) R27-34.

[38] M. Dym, Y. Clermont, Role of spermatogonia in the repair of the seminiferous epithelium following $\mathrm{x}$-irradiation of the rat testis, Am. J. Anat. 128 (1970) 265-282.

[39] K. Furukawa, Y. Hotta, cDNA cloning of a germ cell specific lamin B3 from mouse spermatocytes and analysis of its function by ectopic expression in somatic cells, EMBO J. 12 (1993) 97-106.

[40] K. Furukawa, H. Inagaki, Y. Hotta, Identification and cloning of an mRNA coding for a germ cell-specific A-type lamin in mice, Exp. Cell Res. 212 (1994) 426-430.

[41] T.K. Tang, C.J. Tang, Y.L. Chen, C.W. Wu, Nuclear proteins of the bovine esophageal epithelium. II. The NuMA gene gives rise to multiple mRNAs and gene products reactive with monoclonal antibody W1, J. Cell Sci. 104 (1993) 249-260.

[42] V. Monesi, Ribonucleic acid synthesis during mitosis and meiosis in the mouse testis, J. Cell Biol. 22 (1964) 521-532.

[43] K.O. Söderström, M. Parvinen, RNA synthesis in different stages of rat seminiferous epithelial cycle, Mol. Cell. Endocrinol. 5 (1976) $181-199$.

[44] T.L. Penttilä, L. Yuan, P. Mali, C. Hoog, M. Parvinen, Haploid gene expression: temporal onset and storage patterns of 13 novel transcripts during rat and mouse spermiogenesis, Biol. Reprod. 53 (1995) 499-510.

[45] D. Szöllösi, P. Calarco, R.P. Donahue, Absence of centrioles in the first and second meiotic spindles of mouse oocytes, J. Cell Sci. 11 (1972) $521-541$.

[46] A. Saredi, L. Howard, D.A. Compton, NuMA assembles into an extensive filamentous structure when expressed in the cell cytoplasm, J. Cell Sci. 109 (1996) 619-630.

[47] J. Harborth, S.M. Elbashir, K. Bechert, T. Tuschl, K. Weber, Identification of essential genes in cultured mammalian cells using small interfering RNAs, J. Cell Sci. 114 (2001) 4557-4565.

[48] D.W. Nicholson, N.A. Thornberry, Caspases: killer proteases, Trends Biochem. Sci. 22 (1997) 299-306.

[49] T. Wittmann, M. Wilm, E. Karsenti, I. Vernos, TPX2, A novel Xenopus MAP involved in spindle pole organization, J. Cell Biol. 149 (2000) 1405-1418.

[50] D. Salina, P. Enarson, J.B. Rattner, B. Burke, Nup358 integrates nuclear envelope breakdown with kinetochore assembly, J. Cell Biol. 162 (2003) 991-1001.

[51] T. Raemaekers, K. Ribbeck, J. Beaudouin, W. Annaert, M. Van Camp, I. Stockmans, N. Smets, R. Bouillon, J. Ellenberg, G. Carmeliet, NuSAP, a novel microtubule-associated protein involved in mitotic spindle organization, J. Cell Biol. 162 (2003) 1017-1029. 